\title{
FORMA E IDEOLOGÍA.
}

\section{MECANISMOS DE INTEGRACIÓN Y DE SUMISIÓN \\ EN LECTURA FACIL, DE CRISTINA MORALES}

Form and ideology. Mechanisms of integration and submissiveness in

Lectura fácil, by Cristina Morales

\author{
MARÍA AYETE GIL \\ UNIVERSIDAD DE SALAMANCA (ESPAÑA) \\ mayete.gil@gmail.com http://orcid.org/0000-0002-6638-3281
}

RECIBIDO: 22 DE JULIO DE 2019

ACEPTADO: 6 DE NOVIEMBRE DE 2019

RESUMEN: En este artículo se propone una aproximación a la novela Lectura fácil, de Cristina Morales, desde la asunción de dos presupuestos: el primero, la radical historicidad de la literatura, que nos obliga a atender a las condiciones ideológicas y de producción de las que surge el texto; el segundo, la necesidad de revolucionar la forma literaria para participar en la realidad y transformarla. Tales presupuestos nos llevan, por un lado, al análisis de los procedimientos mediante los que la ficción de Morales desnaturaliza los mecanismos de sumisión y de integración desplegados por el sistema. Por el otro, a esclarecer el modo en que el texto transforma la forma novela mostrándonosla como resultado de un proceso de montaje. Entender la novela como montaje de voces y materiales distintos, reales o ficticios, nos permite, a su vez, entender la realidad como construcción, paso necesario para afrontar el diálogo inevitable entre la ideología de la forma y la ideología del contenido. Solo en este diálogo se desvelan, finalmente, las condiciones y contradicciones de la lógica interna del capitalismo avanzado y se expone la radicalidad del planteamiento de la autora.

PALABRAS ClAVE: Cristina Morales, Lectura fácil, ideología, forma, sumisión.

ABSTRACT: The aim of this article is to study Cristina Morales' novel Lectura fácil from two premises: first, literature's radical historicity, which forces us to pay attention to the ideological and production conditions of the text; secondly, the need to revolutionize the literary form in order to participate in and transform reality. On the one hand, these propositions lead us to analyze the procedures through which Morales' fiction denaturalizes the submissiveness and integration mechanisms displayed by the system. On the other hand, it helps us by clarifying the way in which text transforms the novel form, illustrating it as a result of an assembly process. Understanding the novel as an assembly of different voices and materials, real and/or fictitious, allows us to understand reality as a construction, a necessary step to face the inevitable dialogue between the ideology of form and the ideology of content. Only through this dialogue can we finally learn about the conditions and contradictions of the internal logic of advanced capitalism and the radicalism of the Morales' approach.

Keywords: Cristina Morales, Lectura fácil, ideology, form, submissiveness. 
El derrumbe de la compañía norteamericana Lehman Brothers durante el mes de septiembre de 2008 trajo consigo una recesión económica de consecuencias hasta entonces inauditas en las sociedades del capitalismo avanzado. En España, las políticas sociales se relegaron en favor de los designios de la macroeconomía, y los índices de paro, los desahucios, los recortes y el aumento de la prima de riesgo comenzaron rápidamente a copar la actualidad hasta el punto de tornarse normalidad en los informativos españoles. Sin embargo, la crisis abrió las puertas a nuevos escenarios que la ciudadanía supo aprovechar, y lo hizo movilizándose para tomar las calles el 15 de mayo de 2011, dando inicio al llamado movimiento de los indignados o $15 \mathrm{M}$, que se extendió a lo largo y ancho del territorio español en muy poco tiempo ${ }^{1}$. Pero los indignados no fueron los únicos, a ellos los acompañaron otras movilizaciones ${ }^{2}$, todas con el objetivo de poner el dedo en distintas grietas del sistema español auspiciado por la llamada "Cultura de la Transición” (Martínez, 2012) vigente y hegemónica tras el proceso democrático. Es desde esta coyuntura social, política y económica desde la que comienza a germinar lo que en sus inicios se denominó novelas o narrativas de la crisis; un conjunto de textos "con el que comprender mejor la naturaleza desajustada del mundo posterior al de la crisis financiera" (Valdivia, 2016: 23). Las novelas de la crisis se articulan en torno a la quiebra económica de 2008 y sus consecuencias, pero, al contrario de lo que pudiera esperarse, la mayoría de ellas tan solo han tomado la crisis como tema literario, como si de un telón de fondo se tratara, para construir discursos que dejan de lado la problematización de las causas primeras de tal desajuste en favor de "relatos de la pérdida" de la clase media "basado[s] en la nostalgia por el mundo -y su posición en el mundo- que [ha] quedado atrás” (Becerra Mayor, 2018: 47)3. Esto es, una literatura que, en lugar de modificar los aparatos de producción, en lugar de cuestionar el sistema mostrando sus contradicciones internas y de interpelar al lector, perpetúa la ideología dominante mediante la creación de ficciones cuyas lecturas apelan a la identificación en clave sentimental de los lectores en su individualidad. Una literatura, en definitiva, anestésica cuya función sigue siendo "la de encontrar en la situación política siempre nuevos elementos de entretenimiento para el público" (Benjamin, 2018: 109). Sin embargo, existen otras (pocas) narraciones que sí apuestan por devolver lo social al campo de la literatura y asumen el posicionamiento (con todas sus consecuencias) que tomar la palabra pública conlleva. De la incomprensión del mundo derivado de la crisis económica y del 15M surgió, asimismo, un nuevo escenario para la emergencia de textos otros que todavía está lejos de agotarse. Es desde los márgenes de esa incomprensión, de la necesidad de su denuncia y del anhelo de transformación de donde brotan los intentos de ruptura de una parte de la literatura española actual que, ante los recientes cambios, prefiere crear discursos alternativos que, lejos de quedarse en mera

\footnotetext{
1 Es importante señalar que el $15 \mathrm{M}$ no surge de la nada, al contrario. Desde años anteriores vienen dándose reacciones sociales de distinto calibre (manifestaciones en contra de la intervención en Irak de 2003, reacciones en masa ante los atentados de Atocha del 11 de marzo de 2004, el movimiento V de Vivienda de 2006 o las movilizaciones contra la llamada "ley antidescargas" a partir de 2009) que no hacen sino preparar el terreno para lo que representarán, después, los indignados (Fernández-Savater, 2013: 40).

2 Nos estamos refiriendo a movimientos como Ocupa/Rodea el Congreso, las Marchas de la Dignidad o las Mareas Verde y Blanca.

${ }^{3}$ Sobre la heterogeneidad de estas novelas de la crisis, véase, además del citado Valdivia (2016), López-Terra (2019).
} 
observación, opten por participar en ese cambio4. La última novela de Cristina Morales (Granada, 1985), Lectura fácil (2018), circula por los caminos de esa literatura transformadora, crítica y revolucionaria; una literatura que aborda los conflictos y las contradicciones del sistema de frente y sin tapujos, que cuestiona el orden y el lenguaje que construyen el mundo y que rehúsa ser asumida por el poder en su indagación sobre las prácticas políticas y "los modos de resistir y de imaginar una emancipación posible” (Becerra Mayor, 2019: 52).

Para dilucidar los modos en que la novela pone de relieve esos conflictos y contradicciones de la hegemonía, este estudio va a seguir una metodología analítica centrada en la tesis de la radical historicidad de la literatura. Defender la radical historicidad de la literatura supone, por un lado, aceptar su desnaturalización -es decir, que la literatura no es a-histórica y, por tanto, no ha existido siempre ni tiene que seguir haciéndolo- 5 y, por el otro, entender que esa historicidad $-\mathrm{y}$ no el "contexto"- es la que "constituye la base misma de la lógica productiva del texto: aquello sin lo cual el texto no puede existir" (Rodríguez, 1990: 6). Ahora bien, si la historicidad no es el contexto histórico del texto, ¿de qué hablamos cuando hablamos de historicidad? Nos referimos -siguiendo a Juan Carlos Rodríguez, quien elaboró y desarrolló esta cuestión en Teoría e historia de la producción ideológica - a la lógica interna de la matriz ideológica específica de la que surge ese discurso literario (1990: 15), esto es, a las condiciones, necesidades y contradicciones internas que cada tipo de relaciones sociales reproduce en el nivel de la ideología en un momento histórico dado. Se trata, en este sentido, de asimilar que la historicidad, y con ella, consecuentemente, también la ideología, "es (está) siempre (en) el texto mismo” (Blanco Aguinaga, 1978: 16), con lo que deberemos tenerla presente en el momento de adentrarnos en cualquiera de sus producciones literarias $^{6}$. Sin perder de vista la anterior consideración, completamos la elaboración de nuestro discurso en torno a la novela apoyándonos en teóricos fundamentales, tanto clásicos como contemporáneos, del pensamiento crítico social.

\section{SOBRE LA DECONSTRUCCIÓN DE LOS DISCURSOS Y LOS CUERPOS DISCIPLINADOS}

La reciente publicación de Morales narra un periodo de la vida de cuatro mujeres de la misma familia con grados distintos de "discapacidad intelectual". Nati, Marga, Àngels y Patri son sus nombres. Tras haber pasado por algunos centros para personas con discapacidad (los llamados CRUDIS -Centro Rural para Discapacitados Intelectuales- y RUDIS - Residencia Urbana para Discapacitados Intelectuales-), las mujeres viven ahora en un piso tutelado por la Generalitat de Catalunya en el barrio costero de La Barceloneta, ubicado en la nueva Barcelona de Ada Colau. La discapacidad intelectual de las protagonistas y su desarrollo a lo largo de la novela funcionan a la perfección como arma arrojadiza con la que cargar contra la hipocresía de los discursos institucionales y políticos, tanto tradicionales como de la supuesta "nueva política", sobre la libertad, la democracia, la igualdad, la solidaridad y la justicia. La afilada individualización

\footnotetext{
4 Para un estudio interseccional de nuevas narrativas que toman la crisis como factor de transformación de la subjetividad del individuo y de las relaciones sociales, véase el volumen coordinado por Claesson (2019).

5 Para Benjamin, "no siempre hubo novelas en el pasado y no siempre tendrá que haberlas" (2018: 104). En la misma dirección discurre Juan Carlos Rodríguez al argüir que "la literatura no ha existido siempre" (1990: 5).

6 "No existe una literatura inocente", nos recuerda Becerra Mayor, pues "todas las formas de discurso [...] contienen siempre ideología" (2013: 9).
} 
de cada una de las mujeres, junto a su detallada personalidad, responde a la voluntad, por parte de la autora, de representar, mediante el uso de distintos estilos y formas, modelos varios de insumisión ante la opresión del poder y sus doctrinas de normalización. Tal como afirma Morales, las cuatro "ven el mundo diferente y viven su opresión distintamente" (Corominas i Julián, 2018). Los efectos de esa personal (iy lúcida!) comprensión de su entorno y de los elementos que en él interactúan se transforman en acciones y palabras cuyo objetivo es frenar los sistemáticos ataques con los que el sistema trata de someter y neutralizar la individualidad y el deseo de autodeterminación de las protagonistas.

En "El autor como productor", Walter Benjamin define a los escritores revolucionarios como aquellos que entienden que su misión no es dar cuenta de la realidad, sino combatirla, es decir, no hacer de espectadores de la realidad, sino intervenir en ella (no el autor como observador, sino como productor). ${ }^{7} \mathrm{Y}$ para participar en la realidad y transformarla es necesario romper con los discursos y con las formas hegemónicas, esto es, revolucionar la forma literaria ${ }^{8}$, lo cual no implica, en modo alguno, quebrar la unidad dialéctica, y siempre tensionada, de contenido/forma9. La transformación de la forma en Lectura fácil sobreviene por la construcción de un universo narrativo coral en el que géneros y voces distintas conviven dialógicamente entre sí con dos objetivos fuertemente entrelazados: el primero, dinamitar el interés del sistema dominante capitalista por no "pintar" la realidad "tal como es" (Brecht, 1984: 213); el segundo, exigir al lector su posicionamiento ante lo que se narra tras el proceso de interrupción que los cambios de voz y de género producen.

"Una máxima brechtiana: no conectar con el buen tiempo pasado, sino con el mal tiempo presente" (Benjamin, 2018: 135). El sistema del capitalismo avanzado se sostiene sobre la base de la llamada democracia de consenso o "posdemocracia" (Rancière, 1996), un régimen político y social que, lejos de conectar, como exige Brecht, con los problemas del presente, neutraliza e invisibiliza toda contienda -pues el conflicto desestabilizaría la normalidad del sistema establecidoen favor del consenso entre las partes ${ }^{10}$. Lectura fácil traza justamente el camino opuesto, desafiando al poder y rompiendo con la ideología dominante página tras página mediante la revelación de lo que está oculto. Como explica Adrienne Rich en su ensayo Poetry and Commitment, la literatura nos permite acceder a aquello que "nos está prohibido ver" (2007: 28). Una de las fórmulas que defiende Bertolt Brecht, para quien el concepto de realismo no puede reducirse a moldes estéticos ni técnicos, sino que debe ser "amplio y político", es el llamado realismo combativo. Sus tesis sobre este realismo de combate apuntan, precisamente, en la misma

\footnotetext{
${ }^{7}$ Las palabras exactas de Benjamin son: "Su misión [la de los escritores revolucionarios] no es informar, sino luchar; no jugar a ser el mero espectador, sino intervenir activamente" (2018: 104).

8 Si atendemos a la radical historicidad de la literatura, esta ruptura se traduciría en la creación de una forma distinta a la novela, surgida con la burguesía, o incluso en la destrucción de la literatura, no necesaria ya, quizá, en un futuro con una lógica interna difiera de la actual, producto de un cambio radical en la organización y las formas de producción.

${ }^{9}$ No es este el lugar para desarrollar una crítica de la dialéctica contenido/forma. Véase para ello el capítulo "Forma y contenido" de Literatura y crítica marxista, de Terry Eagleton, y las páginas 43-45 de Julio Rodríguez Puértolas en su texto "La crítica literaria marxista".

10 Es importante señalar que, para Rancière, la política es "la actividad que tiene como racionalidad propia la racionalidad del desacuerdo" (1996:11). Así, según el autor, es el disenso, y no el consenso, el verdadero escenario de la política, pues en tanto praxis permite la reconfiguración del reparto de lo sensible.
} 
dirección que las palabras de Rich: "sólo un realismo inflexible, que lucha contra todo encubrimiento de la verdad, a saber, la explotación y la opresión, puede denunciar y difamar la explotación y opresión del capitalismo" (1984: 277), y en idéntica línea circula Benjamin al afirmar que "no se trata de reproducir situaciones sino de descubrirlas" (2018: 115). El propósito de la novela crítica no debe ser solamente "describir la realidad", insiste Becerra Mayor, "sino [...] describir los velos que la cubren o la opacan” (2015: 15). En el texto de Morales, se combinan géneros que van desde un fanzine anarquista, hasta las actas asamblearias de un grupo okupa, pasando por la transcripción de las declaraciones judiciales de los personajes o una novela escrita mediante el método de "Lectura Fácil"11. La unión de todos ellos provoca una saturación de voces que, colectivamente, deconstruye los discursos sobre los que se sostiene el mundo y su orden por medio de un proceso de desnaturalización. Tal desnaturalización permite acceder a la visión de la realidad como construcción y, por ende, a la construcción de la realidad social. Ahora bien, ¿qué es exactamente lo que el sistema nos prohíbe ver y la novela de Morales nos desvela? La sujeción de los individuos mediante la institucionalización de los cuerpos, el miedo al conflicto y el rechazo de aquello fuera de los parámetros de normalidad establecidos por el sistema, la hipocresía del lenguaje y de los discursos oficiales, y la opresión que cercena al sujeto subalterno son algunos de esos elementos encubiertos que descubre, para el lector, Lectura fácil ${ }^{12}$.

Michel Foucault llama poder disciplinario al poder "que tiene como función principal enderezar conductas" a través de la técnica de la disciplina, que "toma a los individuos como objetos y como instrumentos de su ejercicio" (2012a: 199) para fabricar cuerpos dóciles. En el pensamiento de Foucault, es dócil todo "cuerpo que puede ser sometido, que puede ser utilizado, que puede ser transformado y perfeccionado" (2012a: 159). Un juzgado de instrucción de Barcelona ha abierto un proceso contra Marga (66\% de discapacidad), una de las cuatro mujeres protagonistas de la novela, para conseguir su esterilización. La hipersexualidad (o ninfomanía) de Marga ha hecho sonar las alarmas de la Generalitat, que intentará mediante la esterilización disciplinar a un sujeto que atenta contra la normalidad establecida, a pesar de que, como señala otra de las protagonistas reproduciendo el discurso oficial:

las personas con diversidad funcional intelectual y/o del desarrollo tenemos derecho a una vida afectiva y sexual plena, saludable y satisfactoria, siendo la obligación de las instituciones públicas y privadas dentro del sector desmontar los mitos sobre nuestra sexualidad, ofrecer orientación a las personas de apoyo de los Grupos Autogestores y visibilizar nuestros derechos sexuales y reproductivos (Morales 2018: 147).

\footnotetext{
11 Véase el juego ortográfico del título de la novela, que, significativamente, elimina la mayúscula del segundo término.

$12 \mathrm{El}$ análisis que aquí se propone no agota la potencia de una novela que también cabría analizar en profundidad desde la perspectiva de la interseccionalidad. Esto es, poniendo sobre la mesa los cruces entre género (las protagonistas son mujeres), orientación sexual (la opción del lesbianismo en algunas escenas) y subalternidad (discapacidad). Adoptar, como se está diciendo, una perspectiva de tal naturaleza permitiría, por un lado, problematizar, entre otros aspectos, la vigencia de ciertas normas o valores sociales que no hacen sino perpetuar los parámetros de normalidad legitimados, y, por el otro, ahondar en el rechazo de la novela al pensamiento heteropatriarcal represivo de las sociedades del capitalismo avanzado. En este sentido, la lectura de textos como el de Guzmán y (Lucas) Platero (2012), que trata de dar visibilidad a personas con diversidad funcional no heterosexual, serían fundamentales.
} 
Haciendo oídos sordos a esa supuesta solidaridad, el proceso de esterilización va a ser "el dispositivo biopolítico al que recurr[a] el Estado para ejercer el control sobre un cuerpo y un modo de vivir la sexualidad que excede los márgenes de lo aceptable” (Becerra Mayor, 2019: 2). La administración y los tribunales funcionan como lo que Louis Althusser definió como Aparato represivo de Estado. Si para Althusser, los Aparatos ideológicos de Estado (AIE) son aquellos que funcionan primordialmente con la ideología, "y la ideología con la que funcionan, en realidad está siempre unificada [...] bajo la ideología dominante" (2003: 126), los aparatos represivos de Estado "«funciona[n] mediante la violencia», por lo menos en situaciones límite (pues la represión administrativa, por ejemplo, puede revestir formas no físicas»" (2003: 125). El aparato represivo de Estado de la administración y de los tribunales busca, mediante la violencia médica, transformar un cuerpo desobediente, que transgrede las normas de convivencia estipuladas por el sistema, en cuerpo dócil, esto es, en cuerpo disciplinado e integrado; en otras palabras, institucionalizado. Pero la institucionalización de los cuerpos no se da únicamente en el terreno judicial y hospitalario. No es baladí, en este sentido, que las protagonistas de la novela digan de ellas mismas "me institucionalizaron" (Morales, 2018: 57) cada vez que, o bien son ingresadas en centros de inserción e integración, o bien acuden a programas con los mismos fines. Otro ejemplo claro de los dispositivos estatales de neutralización de la diferencia y homogeneización de los cuerpos lo encontramos en el personaje más crítico y radical de la novela, Nati $(70 \%$ de discapacidad). Nati acude todas las semanas a clases de "danza integrada", una danza que, como su nombre indica, persigue la integración de personas con discapacidad mediante el movimiento de los cuerpos. En palabras del personaje: "va de que los cuerpos y las mentes no normalizados se integren en el sistema gobernante de cuerpos y mentes normales, esto es, respetuosos con las normas" (2018: 182). La danza, como antes la esterilización, lejos de visibilizar a las personas discapacitadas, lo que hace en realidad es desempeñar una función de invisibilización de las diferencias, por eso "a un sordo se le puede proponer seguir el ritmo de la música y a un ciego imitar los movimientos de alguien" (2018: 170). El rechazo sistemático de lo que está fuera de la normalidad mediante la disciplina de los cuerpos viene determinado también en la novela por medio de otros aparatos represivos - pues pueden operar a través de la violencia en algunos casos- e ideológicos de Estado: los CRUDIS y los RUDIS. Tal como advierte Foucault, "la disciplina organiza un espacio analítico" (2012a: 166). En el espacio de estos centros de integración operan, como en escuelas y hospitales, tres principios fundamentales de la disciplina, a saber, la clausura, la división en zonas y la jerarquía. Tales principios dotan a los centros de las herramientas necesarias para organizar y controlar a los internos, así como reajustar hasta homogeneizar sus conductas y personalidades. En la novela de Morales, Àngels (40\% de discapacidad) está escribiendo sus memorias en Lectura Fácil por WhatsApp ${ }^{13}$. En uno de los fragmentos de esas memorias, realiza un claro retrato de la vida en esos centros de internamiento para discapacitados, en los que, ante cualquier desviación, no se duda en aplicar la violencia como medio de sujeción: "[...] la enfermera directamente te clavaba una jeringuilla / que te dejaba

13 La escritura en el método Lectura Fácil se rige por ciertas reglas. Algunas de ellas son el empleo de un estilo directo y conciso, evitar el lenguaje metafórico y abstracto o usar, en la medida de lo posible, palabras simples (si se usan vocablos complejos, estos deben explicarse). En cuanto a criterios de maquetación, los textos en Lectura Fácil no deben justificarse, han de contener márgenes y espacios anchos, y un número limitado de líneas por página, entre otros aspectos. Para más información puede consultarse la página web de la Asociación Lectura Fácil www.lecturafacil.net 
dormido. / Y luego encima te castigaban. / [...] y luego encima te encerraban un rato bajo llave [...]" (Morales, 2018: 341). La disciplina se impone mediante dos mecanismos: el primero, la inyección como instrumento de sumisión de los cuerpos; el segundo, la sanción normalizadora del castigo y su poder correctivo ${ }^{14}$. Ambos actúan con un único fin: distribuir los cuerpos según el principio de lo permitido y de lo no permitido, operando sobre los sujetos para que se ajusten al modelo de la norma, en virtud de la cual se requiere un comportamiento específico en el interior de los centros.

La visibilización, en la novela de Morales, de la sujeción de los individuos mediante la institucionalización de los cuerpos ocurre como reacción al proceso inverso, esto es, la invisibilización de dichos mecanismos de opresión y de dominio por parte del Estado. Vivimos en un sistema en el que "los conflictos y los problemas son fisuras potenciales en el statu quo y su reparto de lugares, tareas y poderes" (Fernández-Savater, 2012: 37); un sistema consensual y desproblematizador en el que cualquier forma de litigio es interpretada según la lógica de la ruptura y el desequilibrio, como amenaza que atenta contra la normalidad (pre)establecida. La democracia de consenso (nos hemos referido a ella con anterioridad) alza sus pilares de contención sobre una férrea base: la proyección e interpretación del orden social en términos de armonía e integración. Pero para crear y mantener erguidos en el tiempo dichos pilares, es necesaria la puesta en funcionamiento de un elemento fundamental: el discurso.

El diccionario de la Real Academia define la retórica como el "arte del bien decir, de dar al lenguaje escrito o hablado eficacia bastante para deleitar, persuadir o conmover" 15 , en otras palabras, un acto de sometimiento por medio del lenguaje que ejecuta todo aquel que emplea la lengua como mecanismo para convencer de una idea previamente asumida por quien toma la palabra. La carga connotativa que poseen las palabras es indudable, y el aprovechamiento de esas connotaciones permite tanto el enmascaramiento como la distorsión de la realidad mediante el discurso. Teniendo esto en cuenta, podemos afirmar que Lectura fácil trata de desenmascarar el falseamiento del lenguaje censurando la hipocresía del eufemismo en favor de la literalidad; esto es, el uso de la retórica para esconder y silenciar. Así, ya en la segunda página de la novela nos topamos con las siguientes palabras de Nati:

Estoy intentando a toda costa ser literal [...]. Cuando era pequeña no entendía las letras de las canciones porque estaban cuajadas de eufemismos, de metáforas, de elipsis, en fin, de asquerosa retórica, de asquerosos marcos de significado predeterminados en los que "mujer contra mujer" no quiere decir dos mujeres peleándose sino dos mujeres follando. Qué retorcido, qué subliminal y qué rancio. Si por lo menos dijera "mujer con mujer"... Pero no: tiene que notarse lo menos posible que ahí hay dos tías lamiéndose el coño (Morales 2018: 14).

La continua problematización del lenguaje ya sea por medio de la reflexión o de la búsqueda de la mayor precisión posible es continua a lo largo del texto. De este modo, la antirretórica se convierte en principio vertebrador de la novela, atravesando, de una manera o de otra, la trayectoria de todas y cada una de las críticas desplegadas en el texto.

\footnotetext{
14 "El castigo disciplinario", advierte Foucault, "tiene por función reducir las desviaciones. Debe, por lo tanto, ser esencialmente correctivo" (2012: 209). [Cursiva en el original]

15 Real Academia Española. (2001). Retórica. En Diccionario de la lengua española (22. ${ }^{2}$ ed.)
} 
Sin embargo, si bien los blancos a los que apunta Morales son sin duda múltiples, hay uno que sobresale por encima de los demás: las mentiras de la democracia y sus lacayos bienestar y solidaridad, términos resignificados por la supuesta "nueva política". Patri (52\% de discapacidad) es un personaje que asimila los términos de la nueva política porque piensa que, quizá, empleándolos ante la jueza que lleva el proceso de esterilización de Marga, pueda recibir un mejor trato. Nada más lejos de la verdad. La retórica derivada del $15 \mathrm{M}$ ha terminado siendo, con el tiempo, neutralizada y absorbida por los mecanismos de institucionalización del sistema, que ha desenfundado sus armas para, con mayor o menor sutileza, descomponer la amenazante subversión que esos nuevos lenguajes supusieron en sus inicios. Pero Morales va un paso más allá y logra insertar la crítica a los conceptos de bienestar y de solidaridad desde un lugar, cuando menos, imprevisto: las asambleas de un grupo anarquista. No obstante, y por si lo anterior no fuera suficiente, la potencia crítica del texto se multiplica al problematizar los discursos supuestamente revolucionarios de estas asambleas de okupación, donde el empleo de una retórica cargada de ironía hace florecer, precisamente, el cuestionamiento de la posibilidad de la horizontalidad del poder. De igual modo, las clases de danza le sirven a la autora para arremeter contra las falsedades del discurso integracionista: "Ella [la profesora de danza] dijo: "Nos quitamos los calcetines" y no "Os quitáis los calcetines", incluyéndose a sí misma en la otredad, y con ello eliminándola, creando un falaz "nosotras" en que profesora y alumnas se confunden" (2018: 19). La pretendida horizontalidad del discurso no pasa desapercibida a oídos de Nati, a quien no tardan en cerrársele las compuertas que marcan el inicio del conflicto ${ }^{16}$. La ideología "buenrollista" de la integración de la nueva política choca sobremanera con la visión de Nati, en cuya radicalidad anida el empeño por reconstruir una forma de pensamiento colectivo que dinamite la verticalidad y se erija sobre individualidades y diferencias.

En una novela en la que la crítica al poder del discurso es fundamental, el análisis de su contraposición -es decir, del silencio- resulta, cuando menos, significativo. Si bien "nombrar, decir quién ha hecho qué, designar el blanco, es una primera inversión del poder, es un primer paso para otras luchas contra el poder" (Foucault, 1990: 16), el silencio es "la censura del inconsciente ideológico” (Becerra Mayor, 2015: 14). Juan Carlos Rodríguez define el inconsciente ideológico como el "diagrama que nos pigmenta la piel, desde el que surge todo [...], y que determina todas nuestras acciones y nuestras producciones textuales” (2002: 37-38). Es decir, la ideología no impuesta de forma vertical por los aparatos de Estado, sino como producto de las relaciones sociales que, inconscientemente, predisponen nuestra forma de ver y de enfrentarnos al mundo. De este modo, si nombrar supone la ruptura con el inconsciente ideológico y, por lo tanto, puede llevar a la trasposición de poderes, callar nos convierte en perpetuadores del sistema, en piezas útiles del engranaje dominante. Aunque en grados distintos, las cuatro mujeres de la novela de Morales, lejos de callar, padecen una lúcida y afilada incontinencia verbal con la que se oponen sin descanso a la dominación y a la opresión física e ideológica. Las voces de Nati, Marga, Patri y Àngels hablan desde la ruptura con el inconsciente ideológico, y solo desde esa ruptura previa son capaces tanto de desarticular los discursos desmovilizadores y mistificadores

\footnotetext{
${ }^{16}$ El personaje de Nati sufre el llamado "síndrome de las compuertas", un síndrome que le impide obedecer una vez se han cerrado las metafóricas compuertas que cubren su rostro, pues a través de ellas observa y percibe la realidad de forma heterodoxa y radical.
} 
dominantes, como de censurar el silencio cómplice de su entorno. Ante el mutismo de sus compañeros de danza integrada, escuchamos de Nati las palabras que siguen:

tengo bien aprendido que el hecho de que los demás callen es una máxima posmoderna neutralizadora de los conflictos [...] sé que estoy ante la enésima demostración práctica de la teoría de la espiral del silencio y que los demás, cuando callan, lo que quieren es que yo también me calle y así todos vivamos calladitos y guapitos (Morales 2018: 183).

En la línea de Pierre Macherey, quien afirma que en el silencio está contenida la ideología, quedando en el vacío lo que nuestro inconsciente ideológico no nos permitiría decir (Eagleton, 1978: 52), Nati concluye su reflexión sobre el silencio apelando, precisamente, a ese poder de la ideología dominante de operar desde el enmudecimiento: "el discurso hegemónico cuando más se impone es cuando no se digna a dirigirte la palabra" (Morales, 2018: 183). En efecto, el silencio opera con dos grandes objetivos: como mecanismo antonomástico de la democracia de consenso, busca mediante su activación el ocultamiento del litigio; como forma del inconsciente ideológico, trata de imponer los límites de lo decible. Los personajes de la novela combaten el silencio con su radical opuesto, que no es la mera palabra, sino la palabra crítica y, por tanto, disidente, de unas voces activas en perpetuo estado de alarma. Sin embargo, Morales parece ser plenamente consciente de la inutilidad del discurso inmóvil, esto es, del espacio que dista entre pensamiento y actuación. Por ello, para eliminar o, cuando menos, reducir la distancia entre el texto y la acción, llama por medio del discurso y la acción de sus protagonistas a la politización no integrada ni integradora desde una escritura con vocación transformadora, pues ya el hecho de la escritura con tal vocación es un hecho transformador en sí, como lo es el mismo hecho de su lectura.

\section{LECTURA FÁCIL O LA TRANSFORMACIÓN DE LA NOVELA}

Según Foucault, el discurso es uno de los principales y más útiles mecanismos de dominación existentes, pues, aparte de su poder de coacción mediante la palabra, implanta una visión determinada de la realidad que permite recorrerla y dominarla (2012b: 17). La visión de la realidad implantada por la democracia de consenso del sistema hegemónico en España es bien clara: vivimos en el mejor de los mundos posibles, nuestro Estado democrático no solo es estable y está fuertemente cohesionado, sino que, además, todas las voces tienen representación en el escenario político. Ahora bien, como apunta Luisa Elena Delgado, "el estado de consenso se sostiene sobre un cómputo equivocado: entender que son todos los que (ya) están, y que (ya) están todos los que son" (2014: 16). Resultado de este cálculo erróneo es la existencia de sujetos como los personajes de Morales, individuos excluidos o subalternos. Si la política rompe con el reparto de lo sensible mostrando lo invisible, y toda ficción es siempre un acto político, entonces mediante la ficción puede reconfigurarse lo sensible (Rancière, 2002: 64)17. Según Rancière, el artista no representa la realidad, sino que produce un arte anti-representativo que muestra el lado oscuro y oculto de esta, ampliando los límites de lo visible y rompiendo con el reparto democrático de consenso. Lectura fácil opera en esa ruptura mediante unos personajes

\footnotetext{
17 En la misma línea apunta Žižek cuando afirma que la lección estética del Holocausto es que "lo que no se puede describir se debería inscribir en la forma artística" (2008: 30), o cuando, citando a Lacan, sostiene que "la verdad tiene la estructura de una ficción" (2008: 28).
} 
disconformes con el lugar que ocupan en el statu quo, a los que se dota de agencia para exigir ser percibidos, escuchados y tenidos en cuenta. La politización de Nati y de Marga sobreviene en el momento en el que se consideran sujetos con el derecho de articular un discurso o bien de emprender una acción con el objetivo de levantar los velos que encubren la normalidad, de desnaturalizar lo antes considerado natural y mostrarlo en su forma original, es decir, como una construcción social, como una forma histórica de poder que permite la opresión por parte de los capacitados hacia los discapacitados. Y tal proceso de desnaturalización no es sino síntoma de la ruptura con el inconsciente ideológico, un inconsciente que, al asumir que la normalización pasa por la sumisión a las normas impuestas por el sistema, dota a la anormalidad de la discapacidad -a las cuatro protagonistas de la novela- de su opuesto, esto es, de una posición fuera del marco integrado e integrador que les permite, precisamente, confrontar lógicas distintas desde parámetros no delimitados en el sistema social vigente. Los personajes de Morales quieren participar en la historia por sí mismos, en primera persona, y no a través de la figura de un mediador que adopte un modelo vertical de representación. Contar la historia desde su punto de vista (Àngels, cabe recordar, es autora de sus propias memorias) supone interrumpir el continuum histórico del relato del progreso, abrir una fisura para mostrar, como el ángel de Benjamin, los excluidos del banquete de nuestro bienestar. En la voz y en los actos de las mujeres de Lectura fácil se muestran, tanto las contradicciones e interferencias del sistema - un sistema que, a pesar de sus "buenas intenciones", sigue marginando e "institucionalizando" a los sujetos discapacitados-, como un intento de democratización de la literatura, pues la literatura se democratiza cuando los excluidos del discurso literario comienzan a hablar.

Ahora bien, cuando el sujeto subalterno aparece en escena, ya sea de forma central o tangencial, corre el riesgo de convertirse en objeto de compasión. La victimización opera neutralizando, vaciando de contenido y de significado político tanto al sujeto como a sus actos, que quedan recluidos en la esfera de la sentimentalidad. Sin embargo, la víctima debe entenderse como sujeto de revuelta, con agencia y, por lo tanto, capaz de desprenderse de la pasividad a la que lo recluye la propia noción de víctima ${ }^{18}$. En este sentido, la escritura de Morales, lejos de cercenar el potencial político de sus protagonistas mediante su victimización -lejos de apelar a la caridad del lector-, las convierte en sujetos de acción en perpetua lucha por su emancipación ${ }^{19}$. No obstante, esta lucha es, asimismo, la lucha por la autodeterminación de los lectores a través de la búsqueda de un nuevo discurso que sirva para la revolución, y la búsqueda de tal discurso sobreviene del intento de transformación del aparato-novela que supone Lectura fácil.

Como se ha apuntado al principio de estas páginas, la actualización de la forma en la obra de Morales ocurre en la convivencia dialógica entre géneros y voces, cuyo objetivo, desarrollado mediante la técnica de la interrupción, es doble: poner sobre la mesa el interés del sistema en ocultar los elementos conflictivos de la realidad y exigir al lector su posicionamiento ante lo que se narra. Como en el teatro épico de Brecht, que promueve la movilización política de sus espectadores a través de las técnicas del distanciamiento y de la interrupción, que buscan evitar la empatía con los actores y permitir la observación desnaturalizada de las situaciones expuestas

\footnotetext{
${ }^{18}$ La distinción de la víctima entre objeto de compasión y sujeto de revuelta es de Traverso (2019).

19 La novela, queda claro, está lejos de retratar a sus protagonistas siguiendo los limitados e infantilizados estereotipos que sí suelen reproducirse a la hora de representar este tipo de subalternidad.
} 
sobre el escenario, la novela trata de activar la conciencia crítica del lector mediante mecanismos análogos. Uno de los objetivos fundamentales del teatro brechtiano reside en sustituir la proyección sentimental del espectador hacia el héroe por su asombro ante el entorno y las condiciones en las que el personaje se mueve (Benjamin, 1970: 10). Ese asombro del espectador, sin el cual no cabría posicionamiento político alguno, lo logra Brecht rompiendo el desarrollo de las situaciones en escena. Al contrario que en el teatro tradicional, en donde las acciones de desarrollan de manera lineal, en el brechtiano se interrumpe consciente y constantemente la acción. Esa ruptura propicia el distanciamiento necesario para que el público reflexione de forma crítica sobre la situación presentada. Benjamin resume el procedimiento con mucha claridad:

El teatro épico [...] avanza en transiciones bruscas. Su forma básica es la sacudida, que se produce al encontrarse las diversas y bien pulidas situaciones de la obra. Las canciones, los carteles pintados, las convenciones gestuales separan una situación de la otra. Así surgen en todas partes intervalos que rompen la ilusión del público. Esos intervalos están reservados para su toma de posición crítica, para su reflexión (1970: 30).

La ruptura del continum escénico resulta esencial, pues supone la chispa que pone en marcha el mecanismo de distanciamiento (extrañamiento) para desactivar esa "ilusión del público" que lo empuja a empatizar sentimentalmente con personajes y contextos. Puede decirse, por tanto, que la técnica del distanciamiento, lejos de naturalizar situaciones y percepciones, lo que hace es, al reducir la obra a un cúmulo de situaciones intercaladas, exponer la naturaleza de la obra artística en tanto construcción artificial, esto es, mostrar al espectador el proceso de producción de la obra. Al entenderse la obra como proceso, esta deja de comprenderse como expresión subjetiva del autor/genio inspirado, y pasa a interpretarse como resultado de un trabajo de carácter colectivo donde se utilizan múltiples técnicas y medios. De esta manera, la obra, finalmente, queda expuesta como fruto de un trabajo de montaje en el que la interrupción queda asimilada, pues "lo montado interrumpe el contexto en el cual se monta" (Benjamin, 2018: 114).

La amalgama de voces y de géneros que irrumpe e interrumpe Lectura fácil fractura el desarrollo de las situaciones de la novela. Si, tal como arguye Benjamin, "citar un texto implica: introducir una ruptura en su contexto" (1970: 11), podemos entender que los fragmentos de las memorias escritas por Àngels, las actas de la asamblea okupa, la transcripción de las declaraciones judiciales de los personajes y el fanzine anarquista actúan como elementos de interrupción del continuum argumental del texto. La incorporación de tales componentes de dislocación tendría dos cometidos: por un lado, mostrar la obra como lo que en efecto es, es decir, como un artificio fruto de un proceso productivo de trabajo colectivo en el que se emplean técnicas de producción distintas. En este sentido, la autora no nos ofrecería una obra que surge directamente de su individualidad psicológica, sino un trabajo de montaje que muestra el carácter dinámico y constructivo de la realidad y su posibilidad representativa. Esta capacidad del montaje de (auto)reconocerse en tanto artificio desactiva la introducción de las situaciones en los contextos naturalizados por las relaciones sociales de clase, permitiendo al lector aquello que, para autores como Eagleton, resulta fundamental -pues "en la medida en que la sociedad política no se reconoce a sí misma como una producción se hace necesario representarla como tal" (2007: 60)-: descubrir la realidad como producción a partir de códigos lingüísticos convencionalizados. El trabajo de Morales por retorcer el lenguaje hasta los límites de la antirretórica responde, precisamente, a ese afán por revelar el disfraz de tales códigos de producción y representación. 
Es ese esfuerzo por posicionarse en las antípodas de la retórica el que, unido a la propia técnica del ensamblaje, nos lleva al segundo cometido del montaje: distanciar, a la manera brechtiana, al lector para su toma de posición ante los sucesos desvelados. Sin embargo, esa toma de conciencia solo puede llevarse a cabo desde la neutralización de la identificación entre lector y personajes, un distanciamiento que Morales refuerza al enfrentarnos a sujetos no victimizados. De esta manera, las constantes interrupciones, sumadas a la desvictimización de las protagonistas del texto, anulan cualquier proyección empático-sentimental del lector con las cuatro mujeres. Como ya se ha dicho, la interrupción no busca el deslumbramiento del lector, sino su posicionamiento en el tablero de la realidad. Y es justamente en el momento de ese posicionamiento del lector cuando el mundo, vuelto fragmentos, se reorganiza. Para Rancière, recordemos, la estética es también política, pues contribuye a la repartición de lo sensible introduciendo lo hasta entonces oculto y permitiendo experiencias no regladas por la clase dominante, "haciendo que sean entendidos como hablantes aquellos que no eran percibidos más que como animales ruidosos" (2011:35). Lectura fácil nos distancia del texto mediante las constantes interrupciones que los cambios de registro y de género suponen, obligándonos, primero, tanto a ver aquello que no nos estaba permitido ver, como a escuchar las voces de aquellos a quienes no se les permitía hablar; segundo, a posicionarnos con respecto a lo que leemos y, tercero, y consecuentemente, a operar en la reconfiguración del mundo que conocemos.

Entender la obra como la estamos entendiendo, es decir, como resultado de un proceso productivo de montaje de voces ficticias y géneros distintos, y no como fruto individual del trabajo de un genio creador, nos permite pensar la forma como ideología. La ideología de la forma, que en Lectura fácil reside tanto en la forma de escribir como en la de montar el texto, conlleva una serie de efectos -ya explicitados, de una manera o de otra, a lo largo de estas páginas- inseparables de la ideología del contenido. Por un lado, desde el momento en que la forma de escritura de la novela se rige por el principio de la antirretórica, se produce una fractura con el inconsciente ideológico que afecta tanto a la forma como al contenido del texto. Y es que en la propia búsqueda de un lenguaje no contaminado por las clases dirigentes reside un contenido que critica destructivamente la apropiación del discurso por parte del poder. Por el otro, la forma de montar el texto supone, de igual manera, la ruptura de la organización de la novela, que a su vez implica la dislocación del modo en que se estructura el mundo. Forma y contenido actúan, de nuevo, ideológicamente al tratar de introducir en la lógica de la comunidad una parte antes sin parte (los individuos subalternos de nombre Nati, Àngels, Patri y Marga); unos sujetos, en realidad, hasta entonces invisibilizados por el régimen falsamente integrador de la democracia consensual. No obstante, y aquí radica la extrema radicalidad de la propuesta de Lectura fácil, las protagonistas de la novela demandan el derecho a no ser partícipes de lo normativo, a no formar parte de un sistema que consideran espurio y de una institución que les coarta libertades. En la inclusión de estos cuerpos singularmente críticos en la coyuntura espaciotemporal específica de la España actual, no se trata de redistribuir lo sensible ni de reordenar el mundo, sino que, más bien, de lo que se trata es de destruirlo o, cuando menos, de dinamitar los cimientos sobre los que se construye. 


\section{CONCLUSIONES}

Tal como se ha argüido al comienzo de estas páginas, sostener la radical historicidad de la literatura nos obliga a atender a las condiciones, necesidades y contradicciones internas que las relaciones sociales reproducen en el nivel de la ideología en un momento determinado para entender la matriz de la que nace el discurso literario. En este sentido, Lectura fácil surge como crítica al molde ideológicamente dominante de la democracia consensual e integradora de la España actual, reproduciendo las contradicciones del sistema para poner en cuestión su naturaleza y puesta en práctica a través del desvelamiento de situaciones y personajes hasta el momento ocultos o, por lo menos, maquillados por la institución y las prácticas sociales que esta inculca y perpetúa.

Los intentos de transformación de las condiciones de producción que el 15M, como momento de repolitización, supuso han permitido la aparición de artefactos literarios como el de Cristina Morales; textos que, lejos de prolongar los mecanismos de opresión y de dominación hegemónicos, rompen con ellos a través de la elaboración de discursos narrativos en donde el montaje de voces ficticias y de géneros transforma y amplía el aparato técnico y formal de la novela. Se trata, por tanto, de transformar ese aparato (la novela) y "dicho aparato será tanto mejor [...] si está en situación de hacer que los lectores o los espectadores se conviertan en colaboradores" (Benjamin, 2018: 113). La transformación de la forma novela en Lectura fácil busca, en última instancia, la creación de un nuevo discurso y de una conciencia colectiva que sirvan para la revolución y la autodeterminación de los lectores. Como sostiene Rancière, "el arte crítico [...] se propone concientizar acerca de los mecanismos de dominación con el fin de convertir al espectador en actor consciente de la transformación del mundo" (2011: 59). Morales reproduce los mecanismos de sumisión en su texto para hacerlos estallar ante el lector, en cuyas manos reside la posibilidad de actuar y participar en la creación de un imaginario diferente. Bajo el convencimiento de la podredumbre que esconden los cimientos sobre los que se yergue el mundo que habitan, a las protagonistas de la novela no les interesa construir, sino destruir para empezar de cero. La invitación a formar parte del proceso radical de modificación que ello supone está más que servida. 


\section{BIBLIOGRAFÍA}

Althusser, Louis (2003). "Ideología y Aparatos Ideológicos de Estado”. Žižek, Slavoj (comp.). Ideología: un mapa de la cuestión. Buenos Aires: FCE: 115-155.

BeCERra MAYOR, David (2013). La novela de la no-ideología. Introducción a la producción literaria del capitalismo avanz̧ado en España. Madrid: Tierradenadie ediciones.

BECERra MAYOR, David (2018). "El relato de la pérdida y las representaciones del fin de la clase media en las novelas de la crisis". Peris, Jaume (ed.). Cultura e imaginación política. Francia/ México: Rilma2/Adehl: 45-62.

BeCerra Mayor, David. "Dispositivos biopolíticos e institucionalización de los cuerpos en Lectura fácil de Cristina Morales". Ínsula. Revista de Letras y Ciencias Humanas, 874-875 (2019): 51-54.

BECERra MAYOR, David (coord.) (2015). Convocando al fantasma. Novela crítica en la España actual. Madrid: Tierradenadie ediciones.

Benjamin, Walter (1970). Brecht: ensayo y conversaciones. Montevideo: Arca Editorial.

Benjamin, Walter (2018). "El autor como productor". Benjamin, Walter. Iluminaciones. Madrid: Taurus: 101-118.

BENJAMIN, Walter (2018). “Conversaciones con Brecht”. Benjamin, Walter. Iluminaciones. Madrid: Taurus: 119-135.

Blanco aguinaga, Carlos (1978). La Historia y el texto literario. Madrid: Nuestra cultura.

BRECHT, Bertolt (1984). El compromiso en literatura y arte. Barcelona: Ediciones Península.

Claesson, Christian (ed.) (2019). Narrativas precarias. Crisis y subjetividad en la cultura española actual. A Coruña: Hoja de Lata.

COROMINAS I Julián, Jordi. "Entrevista Cristina Morales: No quiero reformar nada, quiero destruirlo todo". El Confidencial (2018).

Delgado, Luisa Elena (2014). La nación singular. Fantasías de la normalidad democrática española (1996-2011). Madrid: Siglo XXI.

EAgLETON, Terry (1978). Literatura y crítica marxista. Bilbao: Zero.

Eagleton, Terry. "Brecht y la retórica". Minerva. Revista del Círculo de Bellas Artes 6.07 (2007): 60-62.

FERNÁNDEZ-SAVATER, Amador (2012). "Emborronar la CT (del "No a la guerra" al 15-M)". Martínez, Guillem (coord.). CT o la Cultura de la Transición. Crítica a 35 años de cultura española. Barcelona: Random House Mondadori: 37-51.

FOUCAUlT, Michel (1990). Un diálogo sobre el poder y otras conversaciones. Madrid: Alianza Editorial.

FOUCAULT, Michel (2012a). Vigilary castigar: nacimiento de la prisión. Madrid: Biblioteca Nueva.

FouCAult, Michel (2012b). El poder, una bestia magnifica. Sobre el poder, la prisión y la vida. Argentina: Siglo XXI. 
GuZmán, Paco y Raquel (Lucas) Platero (2012). "Passing, enmascaramiento y estrategias identitarias: diversidades funcionales y sexualidades no-normativas". Platero, Raquel (Lucas) (ed.). Intersecciones: cuerpos y sexualidades en la encrucijada. Barcelona: Bellaterra:125-158.

LÓPEZ-TERRA, Federico (2019). "Narrar la crisis. Representación y agencia en la España poscrisis". Claesson, Christian (ed.). Narrativas precarias. Crisis y subjetividad en la cultura española actual. A Coruña: Hoja de Lata: 121-156.

Martínez, Guillem (2012). CT o la Cultura de la Transición. Crítica a 25 años de cultura española. Barcelona: Random House Mondadori.

MORALES, Cristina (2018). Lectura fácil. Barcelona: Anagrama.

RANCIÈre, Jacques (1996). El desacuerdo. Política y filosofía. Buenos Aires: Nueva Visión.

RANCIÈRE, Jacques (2002). La división de lo sensible. Estética y politica. Salamanca: Consorcio Salamanca.

RANCIÈRE, Jacques (2011). El malestar en la estética. Buenos Aires: Capital Intelectual.

RICH, Adrienne Cecile (2007). Poetry and Commitment: an essay. Nueva York: W. W. Norton \& Company.

RodríGueZ, Juan Carlos (1990). Teoría e historia de la producción ideológica. Madrid: Akal.

Rodríguez, Juan Carlos (2002). De qué hablamos cuando hablamos de literatura. Granada: Comares.

RODRÍGuez PuÉRTOlAs, Juan Carlos. "La crítica literaria marxista". Revista de crítica literaria marxista 1 (2008): 26-63.

SPIVAK, Gayatri Chakravorty. “¿Puede hablar el subalterno?”. Revista Colombiana de Antropología 39 (2003): 297-364.

Traverso, Enzo. Melancolía de irquierda. Después de las utopias. Barcelona: Galaxia Gutenberg.

VALDIVIA, Pablo. "Narrando la crisis financiera de 2008 y sus repercusiones”. 452 F. Revista de Teoría de la literatura y Literatura comparada 15 (2016): 18-36.

ŽIŽEK, Slavoj (2008). "Arte e ideología en Hollywood. Una defensa del platonismo”. Žižek, Slavoj, Jorge Alemán y César Randueles. Arte, ideología y capitalismo. Madrid: Círculo de Bellas Artes: 11-49. 